Terbit online pada laman web jurnal: http://jurnal.iaii.or.id

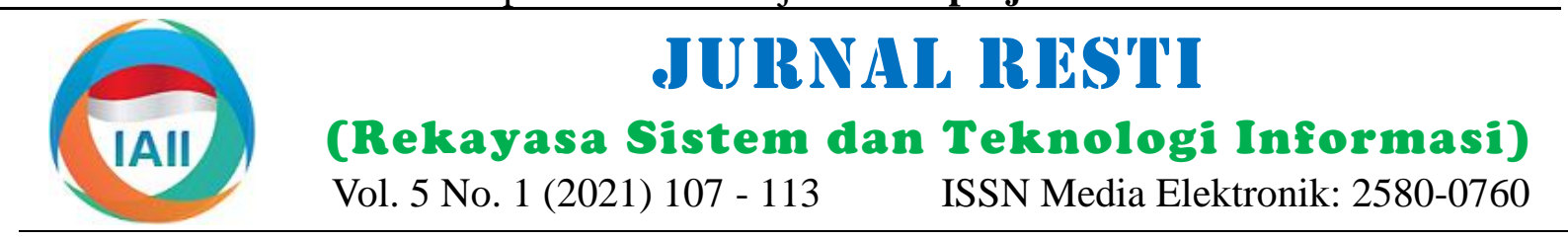

\title{
Pendeteksian Septoria pada Tanaman Tomat dengan Metode Deep Learning berbasis Raspberry Pi
}

\author{
Kahlil Muchtar ${ }^{1}$, Chairuman ${ }^{2}$, Yudha Nurdin ${ }^{3}$, Afdhal Afdhal ${ }^{4}$ \\ 1,2,3,4 Teknik Elektro dan Komputer, Fakultas Teknik, Universitas Syiah Kuala \\ ${ }^{1,4}$ Pusat Riset Telematika, Universitas Syiah Kuala \\ 1'kahlil@unsyiah.ac.id, ${ }^{2}$ chairuman@mhs.unsyiah.ac.id, ${ }^{3}$ yudha.nurdin@unsyiah.ac.id, ${ }^{4}$ afdhal@unsyiah.ac.id
}

\begin{abstract}
Tomato is a horticultural commodity that has the potential to be developed, because it has high economic value, and is also much needed to meet the needs of both industry and households. However, tomato plants still require serious handling in increasing the yields. Data from the Central Bureau of Statistics shows that the number of tomatoes produced is not in accordance with a large number of market demands, resulting from the decrease of tomato yields. One of the obstacles in increasing tomato production is that the crops are attacked by septoria leaf spot disease due to the fungus or the fungus Septoria Lycopersici Speg. Most farmers have limited knowledge of the early symptoms, which are not obvious, and also facing difficulty in detecting this disease earlier. The problem has been causing disadvantages such as crop failure or plant death. Based on this problem, a study will be conducted with the aim of designing a tool that can be used to detect septoria leaf spot disease based on deep learning using the Convolutional Neural Network (ConvNets or CNN) model, where an algorithm that resembles human nerves is one of the supervised learning and widely used for solving linear and non-linear problems. In addition, the researcher used the Raspberry Pi as a microcontroller and used the Intel Movidius Neural Computing Stick (NCS) which functions to speed up the computing process so that the detection process is easier because of its portable, fast and accurate nature. The average accuracy rate is $95.89 \%$ with detection accuracy between $84.22 \%$ to $100 \%$.
\end{abstract}

Keywords: septoria, deep learning, raspberry pi, CNN, Intel Movidius Neural Computing Stick

\begin{abstract}
Abstrak
Salah satu komoditas hortikultura sayuran yang memiliki potensi untuk dikembangkan adalah tanaman tomat, karena memiliki nilai ekonomis yang tinggi, juga banyak dibutuhkan dalam memenuhi kebutuhan baik dalam industri maupun rumah tangga. Namun, tanaman tomat masih memerlukan penanganan serius dalam meningkatkan hasil. Data dari Badan Pusat Statistik menunjukkan bahwa jumlah tomat yang diproduksi tidak sesuai dengan banyaknya permintaan pasar, hal ini karena hasil produksi tomat menurun. Salah satu kendala dalam peningkatan hasil produksi tomat yaitu, tanaman terserang penyakit bercak daun septoria akibat cendawan atau jamur Septoria Lycopersici Speg. Keterbatasan pengetahuan petani akan gejala awal yang tidak tampak jelas dan sukarnya mendeteksi secara cepat terhadap penyakit ini, menyebabkan kerugian seperti; gagal panen ataupun matinya tumbuhan. Berdasarkan masalah tersebut, maka akan dilaksanakan sebuah penelitian dengan tujuan merancang alat yang dapat digunakan untuk mendeteksi penyakit bercak daun septoria berbasis pembelajaran mendalam dengan menggunakan model Convolutional Neural Network (ConvNets atau CNN), dimana algoritma yang menyerupai saraf manusia ini merupakan salah satu pembelajaran terawasi dan banyak digunakan untuk pemecahan masalah linear maupun nonlinear. Selain itu, peneliti memanfaatkan Raspberry Pi sebagai mikrokontroler serta menggunakan Intel Movidius Neural Computing Stick (NCS) yang berfungsi untuk mempercepat proses komputasi sehingga proses pendeteksian lebih mudah karena sifatnya yang portable, cepat dan akurat. Tingkat akurasi rata-rata yang dihasilkan adalah 95.89\% dengan akurasi perdeteksi antara $84.22 \% \mathrm{~s} / \mathrm{d} 100 \%$.
\end{abstract}

Kata kunci: CNN, deep learning, Intel Movidius Neural Computing Stick, raspberry pi, septoria

\section{Pendahuluan}

Tanaman tomat menjadi salah satu komoditas hortikultura sayuran yang potensial untuk dikembangkan. Selain menjadi salah satu komoditas yang bernilai ekonomis tinggi, tomat juga banyak dibutuhkan dalam memenuhi kebutuhan secara nasional, baik dalam industri pengolahan makanan, konsumsi

Diterima Redaksi: 12-01-2021 | Selesai Revisi: 04-02-2021 | Diterbitkan Online: 20-02-2021 
rumah tangga, maupun campuran bahan olahan [1]. secara langsung tanpa menggunakan fitur hand-crafted Namun demikian, tanaman tomat masih memerlukan yang dibuat [7]. Pembelajaran mendalam memberikan penanganan serius dalam hal meningkatkan hasil buah hasil yang baik dalam dunia akademik dan industri [7]. guna memenuhi permintaan yang terus meningkat [2]. Pertama, sejumlah besar data dihasilkan setiap hari Faktanya, peningkatan kebutuhan tomat ini sering tidak sehingga data tersebut dapat digunakan untuk melatih diimbangi dengan peningkatan produksi [3].

Berdasarkan data Badan Pusat Statistik (2019) produksi tanaman tomat nasional selama 10 tahun terakhir mengalami fluktuasi atau naik-turunnya hasil produksi. Produksi tomat yang dihasilkan pada tahun 2012 adalah 893.504 ton, meningkat menjadi 992.780 ton pada tahun 2013. Pada tahun 2014-2015 mengalami penurunan Beberapa metode telah digunakan untuk mendeteksi menjadi 877.801 ton, dan meningkat menjadi 883.242 bercak daun septoria, akan tetapi semuanya masih ton pada tahun 2016 [4]. Selain produksi tanaman tomat menggunakan sistem yang masih manual dan butuh yang selalu mengalami fluktuasi, data nasional waktu lama untuk mengetahuinya, sehingga proses menunjukkan bahwa konsumsi tomat pada tahun 2016 pendeteksian membutuhkan waktu yang lebih lama. mencapai 1.152 .790 ton sedangkan hasil produksinya Salah satu cara untuk mempercepat proses deteksi dalam sebanyak 883.242 ton, hal ini menunjukkan terjadinya metode pembelajaran mesin adalah menggunakan perbedaan yang cukup besar antara ketersediaan tomat OpenVINO (Open Visual Inference and Neural Network dengan permintaan.

Salah satu faktor pembatas dalam peningkatan produksi tanaman tomat di Indonesia adalah penyakit bercak daun septoria. Menurut Gleason dan Edmunds (2006) penyakit bercak daun septoria merupakan penyakit utama dan paling umum menyerang tanaman tomat [5]. Penyakit ini merupakan penyakit yang disebabkan oleh serangan jamur Septoria Lycopersici Speg dimana penyakit ini menyerang dan merusak daun tanaman tomat baik tua ataupun muda. Gejala penyakit diawali dengan adanya bercak kecil berupa lepuhan berair, kemudian cepat berkembang menjadi bercak melingkar Penelitian sebelumnya membahas tentang rancang dengan diameter sekitar $0.30 \mathrm{~cm}$. Luka yang terjadi akan bangun purwarupa pendeteksi penyakit pada tanaman berkembang berwarna kelabu dengan warna putih di tomat dengan metode pengolahan citra digital berbasis pusatnya dan berwarna gelap di tepinya. Umumnya, IOT (Internet of Things) yang dilakukan oleh [10]. Hasil penyakit ini menyerang daun bagian bawah batang dan penelitian ini menunjukkan bahwa sistem yang dibuat akan terus berkembang ke bagian atas apabila cuaca berbasis IOT dengan menggunakan metode pengolahan hujan berlangsung.

Penyakit bercak daun septoria bila dibiarkan akan menyebabkan serangan berat, antara lain: daun menguning, menggulung, dan dapat gugur bahkan dapat merugikan petani seperti gagal panen [6]. Permasalahan ini dapat terjadi karena kurangnya pengetahuan petani terhadap gejala awal yang tidak tampak jelas dan sukarnya mendeteksi secara cepat terhadap jenis jamur yang menyerang tanaman. Maka dari itu, dibutuhkan deteksi gejala penyakit bercak daun septoria pada tanaman tomat untuk mengurangi dampak buruk dari penyakit ini terhadap hasil produksi.

citra digital dapat mendeteksi penyakit bercak daun septoria dengan tingkat akurasi sebesar 67\%. Persamaan penelitian terdahulu dengan penelitian yang akan dilakukan terletak pada penyakit dan tanaman yang digunakan. Adapun yang membedakan penelitian sebelumnya dengan penelitian yang akan dilakukan adalah model atau metode yang digunakan untuk mendeteksi penyakit daun septoria pada tanaman tomat. Pada [10], penulis menggunakan sebuah pendekatan pembelajaran mesin konvensional (machine learning) dalam proses deteksi. Namun demikian, seperti yang telah dijelaskan pada [11] [12] [13], metode pembelajaran mendalam (deep learning) mampu Identifikasi penyakit ini dilakukan menggunakan mengungguli metode konvensional dalam hal akurasi. metode pembelajaran mendalam (deep learning), Salah satu model deep learning yang disebut CNN dimana pendekatan ini didasarkan pada pembelajaran sangat bagus untuk menemukan fitur yang baik pada mesin (machine learning) dan visi komputer (computer citra ke lapisan berikutnya untuk membantu hipotesis vision) untuk membangun pengklasifikasian penyakit nonlinier yang dapat meningkatkan kekompleksitasan dengan hanya menggunakan citra daun sebagai sebuah model.

masukannya. Keuntungan dari pembelajaran mendalam adalah kemampuan untuk mengeksploitasi data mentah

Pada [8] membahas tentang pengklasifikasian dan visualisasi gejala penyakit pada tanaman tomat 
menggunakan pembelajaran mendalam (deep learning). bagian, $80 \%$ dari citra digunakan sebagai data latih Akurasi terbaik dalam model dangkal adalah 95,476 (training data) dan 20\% dari citra digunakan sebagai berbanding 99,185 dalam pembelajaran mendalam. data uji (testing data). Data yang dilatih adalah citra Persamaan penelitian terdahulu dengan penelitian yang daun tanaman tomat normal dan daun tanaman tomat akan dilakukan terletak pada penggunaan model deep yang terinfeksi bercak daun septoria dengan jumlah learning dengan metode convolutional neural network masing-masing 1591 dan 1771 citra. Selanjutnya data $(C N N)$. Adapun yang membedakan penelitian terdahulu dilatih menggunakan model Sequential [12], dengan penelitian yang akan dilakukan ada pada InceptionV3 [13] dan EfficientNet [14] dengan ukuran klasifikasi deteksi penyakit tanaman tomat yang tidak batch size 16 serta depth 3.

spesifik pada satu jenis penyakit daun.

Selain itu, pada [11] membahas tentang deteksi penyakit pada tanaman jagung menggunakan metode $C N N$. Hasil penelitian ini menunjukkan bahwa $C N N$ memiliki akurasi sebesar $99 \%$ dalam mendeteksi penyakit tanaman jagung. Yang membedakan penelitian ini dengan penelitian yang akan dilakukan adalah objek yang digunakan berupa tanaman jagung.

\section{Metode Penelitian}

Objek pada penelitian ini adalah pendeteksian penyakit bercak daun septoria pada daun tomat dengan menggunakan visi komputer dan algoritma $C N N$.

Gambaran umum sistem dapat dilihat seperti pada Gambar 1. Input yang akan dimasukkan ke dalam sistem adalah berupa citra yang ditangkap kamera. Output dari sistem ini adalah berupa citra yang sudah diberi label keterangan terinfeksi penyakit septoria atau tidak. Sistem dapat mengenali penyakit septoria dengan bantuan dataset. Dataset yang digunakan pada penelitian ini berupa kumpulan citra digital yang diperoleh dari website Kaggle $^{l}$. Dataset ini yang kemudian digunakan untuk melatih sistem agar dapat mengenali penyakit septoria. Penelitian ini menggunakan algoritma CNN untuk mengenali penyakit septoria dengan jarak serta pencahayaan yang cukup serta OpenVINO untuk inference model yang digunakan, sehingga mendapatkan hasil deteksi yang maksimal.

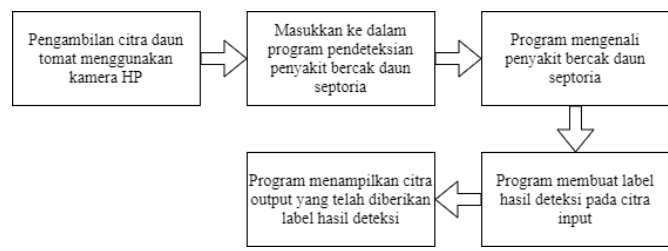

Gambar 1. Blok Diagram Sistem Pendeteksian

Penyakit Septoria

2.1. Konfigurasi Dataset hama Septoria pada tanaman tomat

Kumpuluan citra daun tomat yang akan digunakan diunduh dari website Kaggle. Sebelumnya, pra-proses dijalankan agar data yang digunakan memiliki dimensi yang sama. Setelah dilakukan pra-proses, dataset yang memiliki dua kelas yakni daun tomat normal dan daun tomat terinfeksi bercak daun septoria dibagi menjadi dua

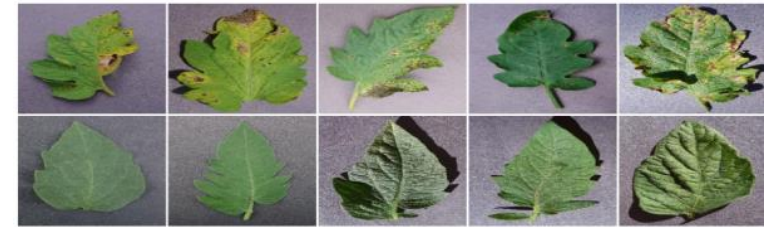

Gambar 2. Dataset Daun Tomat

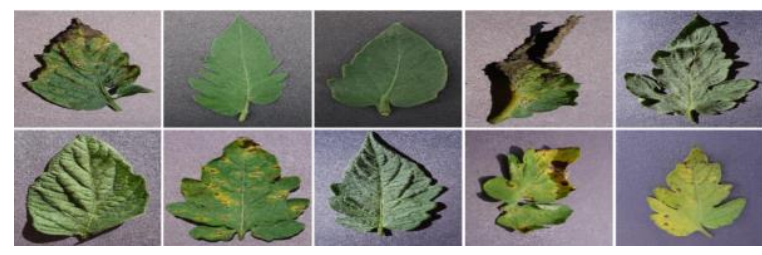

Gambar 3. Sampel Data Training (baris pertama) dan Testing (baris kedua)

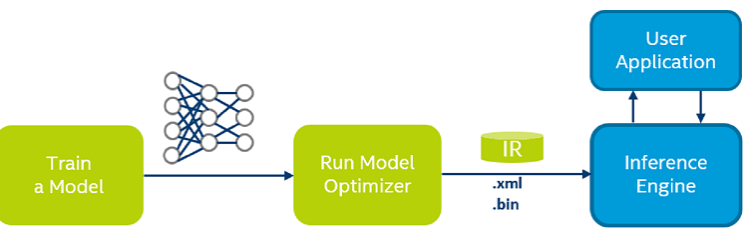

Gambar 4. Alur Optimalisasi Model Menggunakan OpenVINO

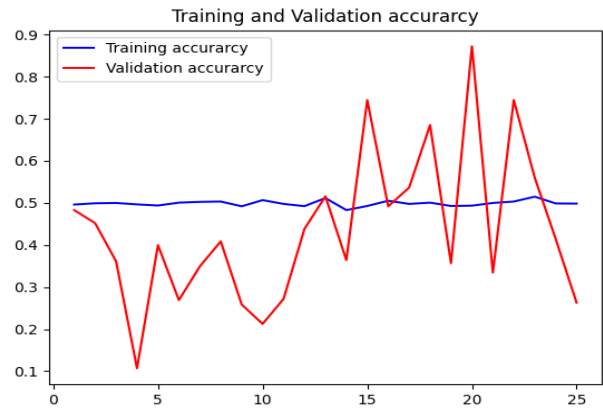

Gambar 5. Perbandingan training dan validation accuracy Sequential

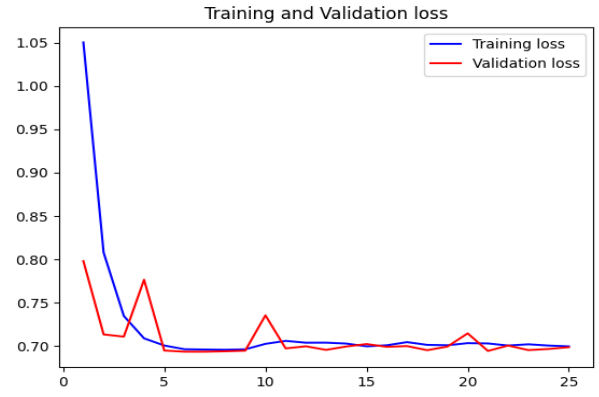

Gambar 6. perbandingan training dan validation loss Sequential

\footnotetext{
${ }^{1}$ https://www.kaggle.com/
} 


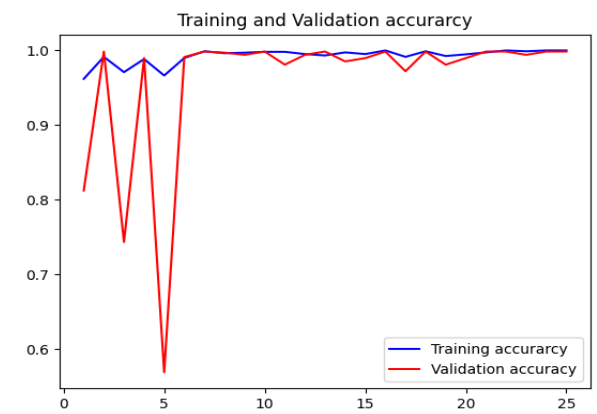

Gambar 7. perbandingan training dan validation accuracy Inception $\mathrm{V} 3$

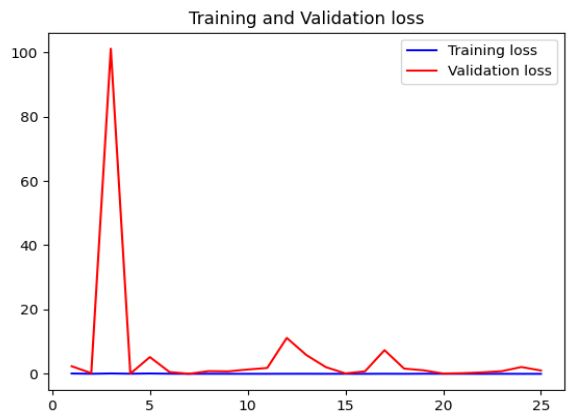

Gambar 8. perbandingan training dan validation loss InceptionV3

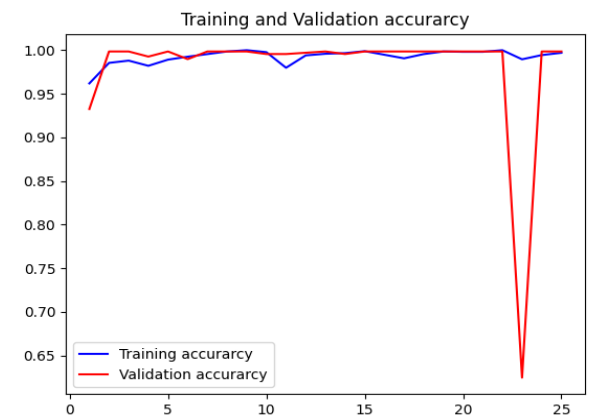

Gambar 9. perbandingan training dan validation accuracy EfficientNet

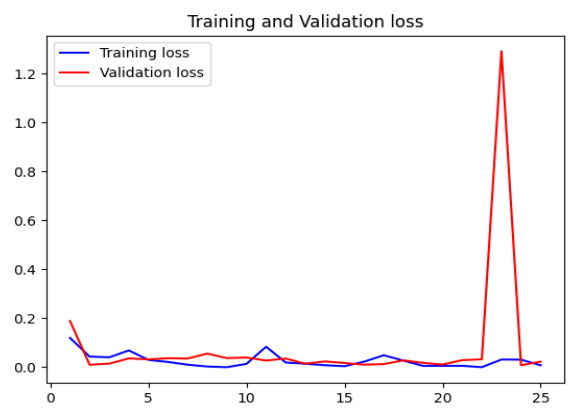

Gambar 10. perbandingan training dan validation loss EfficientNet

Seperti yang terlihat pada Gambar 5 hasil pelatihan menggunakan model Sequential menghasilkan nilai perbandingan akurasi training dan validasi yang tidak stabil dimana nilai akurasi pelatihan sekitar 0,5 dan nilai akurasi validasi mengalami perubahan yang signifikan. Gambar 6 memperlihatkan proses pelatihan menggunakan model Sequential menghasil nilai loss cukup besar yaitu diatas 0,70 . Pada gambar 7 dan 8 , pelatihan menggunakan model InceptionV3 dijelaskan. Serta pelatihan menggunakan model EfficientNet seperti yang terlihat pada gambar 9 dan 10 memiliki nilai akurasi yang stabil di 1,00 dan nilai loss yang kecil dengan rata-rata nilai loss adalah 0 . Tingkat akurasi uji untuk masing-masing model setelah dilatih dan dilakukan pengujian adalah $77,49 \%$ untuk model Sequential, $97.80 \%$ untuk model InceptionV3 dan $98.80 \%$ untuk model yang dilatih menggunakan model EfficientNet. Tiga model yang diuji memperlihatkan bahwa dua model yaitu InceptionV3 dan EfficientNet memiliki akurasi uji yang lebih tinggi dibandingkan dengan Sequential. Penelitian ini memilih model yang dilatih menggunakan InceptionV3 karena EfficientNet sendiri masih belum didukung oleh teknologi OpenVINO, sehingga model EfficientNet tidak dapat digunakan untuk optimasi menggunakan inference engine pada OpenVINO.

InceptionV3 adalah sebuah model deep convolutional network yang dikembangkan oleh google memenuhi ImageNet Large Visual Recognition Challenge pada tahun 2012. Model inception menggunakan beberapa filter pada layer convolutional, tidak seperti convolutional layer biasa. Hasil dari beberapa filter tersebut dijadikan satu lagi menggunakan Concat Channel sebelum masuk kedalam iterasi berikutnya [13]. InceptionV3 merupakan gabungan seluruh perbaikan dari model sebelumnya yang disebut dengan InceptionV2. Ada beberapa hal yang diusulkan, seperti konsep RMSProp Optimizer dan Label Smoothing. Pada dasarnya, konsep label smoothing adalah sebuah upaya untuk mencegah overfitting, yang mana komponen reguralizing akan ditambahkan ke loss formula.

Tujuan dari model inception adalah untuk bertindak sebagai multi-level feature extractor dengan menghitung filter-filter convolutions dalam modul yang sama. Hasil dari filter-filter tersebut kemudian ditumpukkan kedalam dimensi channel sebelum dimasukan ke dalam lapisan selanjutnya [13].

Model yang telah berhasil dilatih akan disimpan dalam format h5 yang selanjutnya akan diubah menjadi Intermediate Representation (IR) menggunakan OpenVINO. Pada akhirnya, model ini dapat digunakan pada inference engine OpenVINO di dalam Intel Movidius NCS. Hasil dari optimasi model menggunakan OpenVINO akan memberikan file .xml yang berisi topologi, layer, connectivity dan parameter serta file .bin yang berisi weight dan bias.

\section{Hasil dan Pembahasan}

Sistem yang dihasilkan berfungsi untuk mendeteksi penyakit bercak daun septoria pada tanaman tomat berdasarkan kumpulan citra yang telah dilatih pada tahap pelatihan dataset. Luaran dari penelitian ini adalah sistem yang dapat digunakan untuk mendeteksi penyakit bercak daun septoria pada tanaman tomat dengan efisien 
dan dapat digunakan pada sektor pertanian. Sistem pendeteksian penyakit bercak daun septoria pada tanaman tomat menggunakan bahasa pemrograman Python dengan modul OpenCV. Sistem ini dijalankan dengan menerima masukan (input) berupa citra daun tomat yang diambil dari kamera. Citra daun tomat kemudian akan diproses oleh sistem sehingga menghasilkan luaran (output) citra daun tomat yang sudah diberi label sesuai dengan hasil deteksi. Hasil pendeteksian penyakit bercak daun septoria pada tanaman tomat yang dihasilkan dapat dilihat pada Gambar 13 dan Gambar 14.

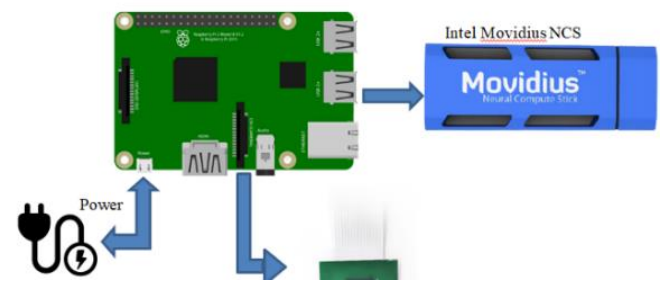

Gambar 11. Rancang Komponen Perangkat Keras

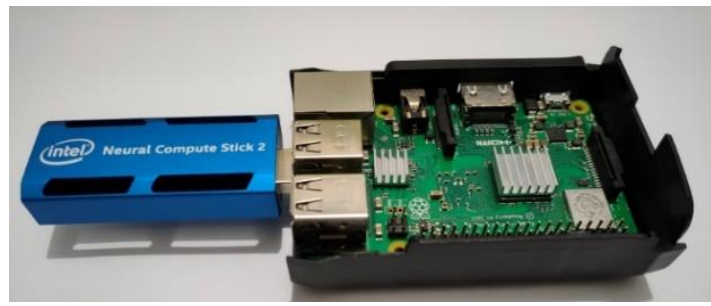

Gambar 12. Hasil Rancang Perangkat Keras

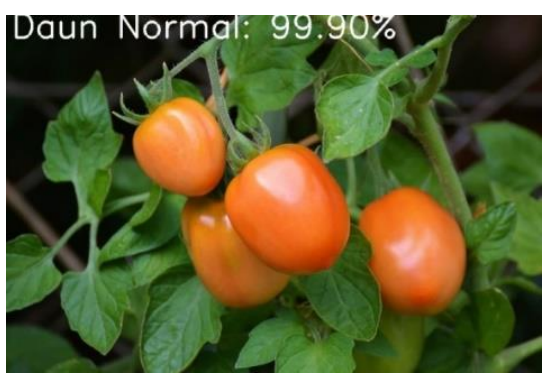

Gambar 13. Hasil deteksi daun tomat normal

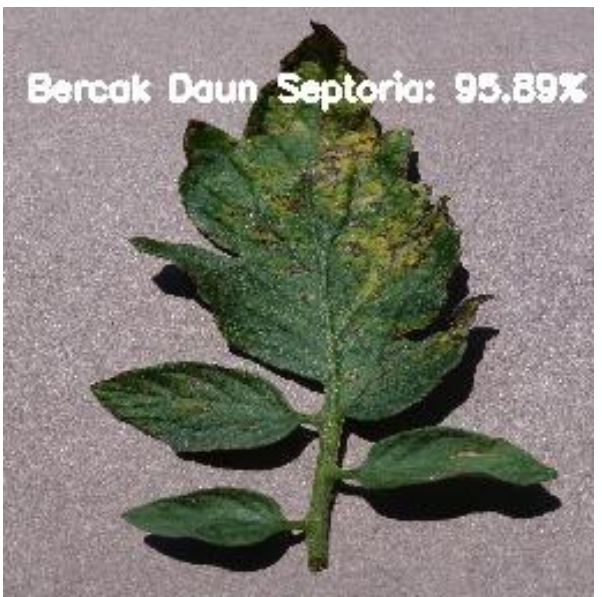

Gambar 14. Hasil deteksi daun tomat terjangkit penyakit bercak daun

septoria
Tabel 1. Hasil pengujian sistem pendeteksian septoria

\begin{tabular}{|c|c|c|c|c|}
\hline No & Citra Input & Citra Output & $\begin{array}{c}\text { Hasil } \\
\text { Deteksi }\end{array}$ & Keterangan \\
\hline 1 & & & $95.89 \%$ & Septoria \\
\hline 2 & & & $86.62 \%$ & Normal \\
\hline 3 & & & $88.67 \%$ & Normal \\
\hline 4 & & & $100 \%$ & Septoria \\
\hline 5 & & & $84.22 \%$ & Normal \\
\hline 6 & & & $87.74 \%$ & Normal \\
\hline 7 & & & $98.09 \%$ & Septoria \\
\hline 8 & & & $99.90 \%$ & Septoria \\
\hline 9 & & & $95.89 \%$ & Normal \\
\hline 10 & & & $99.70 \%$ & Normal \\
\hline 11 & & & $88.67 \%$ & Normal \\
\hline 12 & & & $93.60 \%$ & Normal \\
\hline 13 & & & $100 \%$ & Septoria \\
\hline 14 & & & $99.90 \%$ & Septoria \\
\hline
\end{tabular}




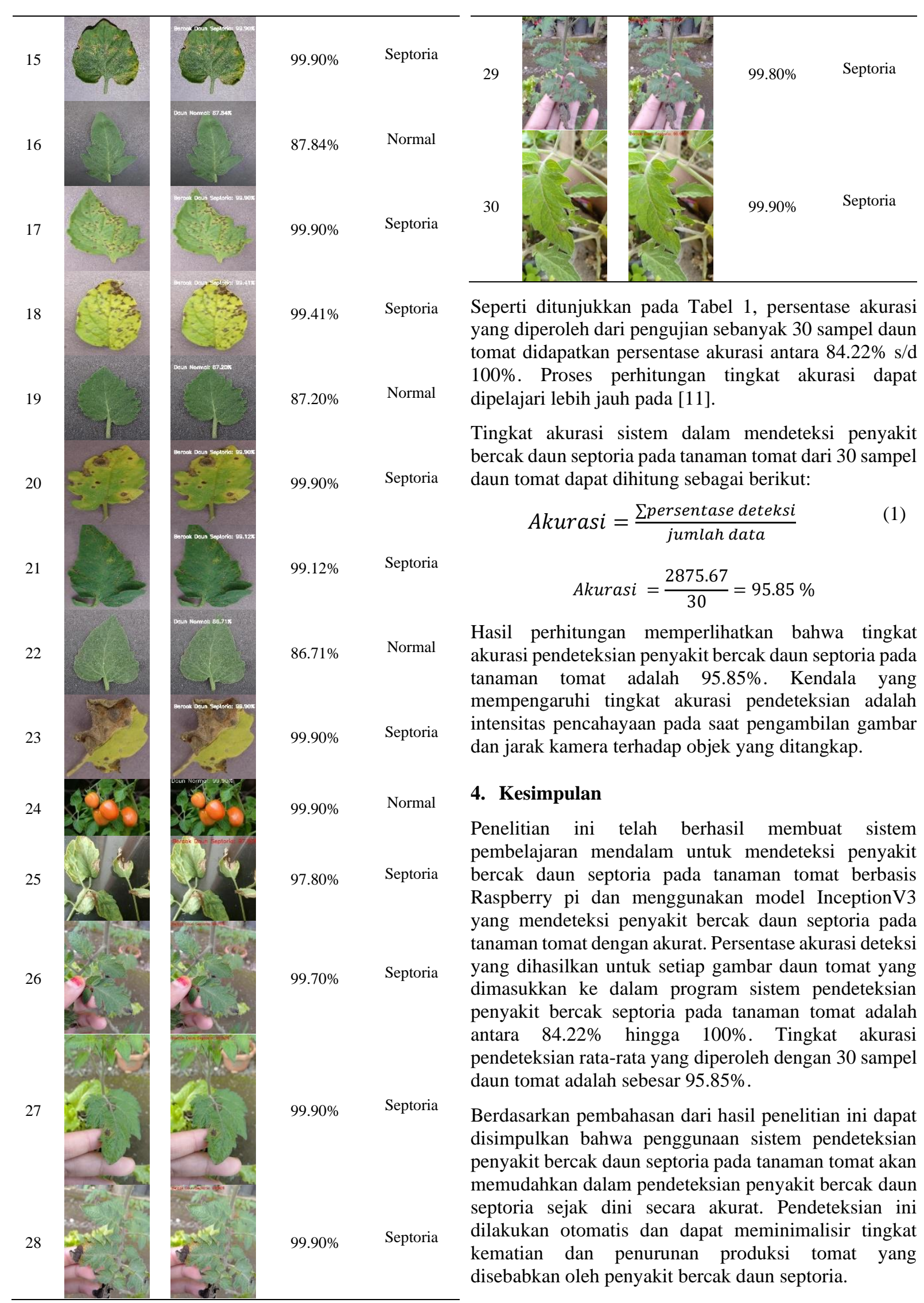




\section{Daftar Rujukan}

[1] E. Latifah, H. A. Dewi, P. B. Daroini, A. Z. Zakariya, A. L. Hakim and J. Mariyono, "Uji Teknis dan Ekonomis Komponen Pengendalian Hama Penyakit Terpadu pada Usaha Tani Tomat," Agrovigor: Jurnal Agroekoteknologi, vol. 11, no. 1, pp. 1-8, 2018.

[2] I. Marina, "Model Kapasitas Produksi Tomat di Sentra Produksi Kabupaten Majalengka," Agrivet: Jurnal Ilmu-Ilmu Pertanian dan Peternakan (Journal of Agricultural Sciences and Veteriner), vol. 7, no. 1, 2019.

[3] E. M. Ruth Feti Rahayuniati, "Pengendalian Penyakit Layu Fusarium Tomat: Aplikasi Abu Bahan Organik dan Jamur Antagonis Control of Tomato Fusarial Wilt: Application of Organic Ash and Antagonistic Fungi," Pembangunan Pedesaan, no. 1, 2009.

[4] B. P. S. R. Indonesia, Statistik Hortikultura 2019, Jakarta: BPS, 2019.

[5] I. R. Sastrahidayat, Penyakit Tanaman Sayur-sayuran, Malang: Universitas Brawijaya Press, 2013.

[6] S. N. Rohmah, "Sistem Pakar Diagnosa Penyakit Pada Tanaman Tomat Dengan Metode Certainty Factor," STMIK Sinar Nusantara, Surakarta, 2017.

[7] H. Al-Hiary, S. Bani-Ahmad, M. Reyalat and M. B. a. Z. ALRahamneh, "Fast and Accurate Detection and Classification of Plant Diseases," International Journal of Computer Applications, vol. 17, no. 1, pp. 31-38, 2011.

[8] M. Brahimi, K. Boukhalfa and A. Moussaoui, "Deep Learning for Tomato Diseases: Classification and Symptoms Visualization," Applied Artificial Intelligence, vol. 31, no. 4, p. 299-315, 2017.

[9] A. Nanjappa, Caffe2 Quick Start Guide: Modular and Scalable Deep Learning Made Easy, U.S: Packt Publishing Ltd, 2019.

[10] F. Abdussalam and D. Hirawan, "Rancang Bangun Purwarupa Pendeteksi Penyakit Pada Daun Tanaman Tomat Dengan Metode Pengolahan Citra Digital Berbasis Iot," Jurnal Ilmiah Komputer dan Informatika (KOMPUTA), 2018.

[11] A. Hidayat, U. Darusalam and I. Irmawati, "Detection of Disease on Corn Plants Using Convolutional Neural Network Methods," Jurnal Ilmu Komputer dan Informasi, vol. 12, no. 1, pp. 51-56, 2019.

[12] L. Denoyer and P. Gallinari, "Deep sequential neural network," arXiv preprint arXiv:1410.0510, 2014.

[13] C. Szegedy, V. Vanhoucke, S. Ioffe, J. Shlens and Z. Wojna, "Rethinking the inception architecture for computer vision," in Proceedings of the IEEE conference on computer vision and pattern recognition, Las Vegas, Nevada, 2016.

[14] M. Tan and Q. V. Le., "Efficientnet: Rethinking model scaling for convolutional neural networks," arXiv preprint arXiv:1905.11946, 2019. 